\title{
Activities of Lactate Dehydrogenase, Methemoglobin, Carboxyhemoglobin and Sulfhemoglobin Concentrations in the Blood of Albino Rats Exposed to Cashew Seed Fume
}

\author{
Makinwa Tunmise Tope*, Ibiyemi David Adedotun, Alabi Toyin Dorcas, \\ Okunade Muda Bode, Oniwon Wisdom Otaru, Adeusi Tomilola Esther \\ Department of Chemical Sciences, College of Natural and Applied Sciences, Achievers University, Owo, \\ Ondo State, Nigeria \\ Email: *makinwatope@yahoo.com
}

Received 26 December 2015; accepted 10 January 2016; published 14 January 2016

Copyright (C) 2016 by authors and OALib.

This work is licensed under the Creative Commons Attribution International License (CC BY). http://creativecommons.org/licenses/by/4.0/

\section{(c) (i) Open Access}

\begin{abstract}
Smoke produced in cashew processing factories during roasting of the seed contains toxic chemicals which have adverse health effects on workers exposed to it. This study investigated the effect of cashew seed fume on lactate dehydrogenase (LDH) activity, methemoglobin (Hi), carboxyhemoglobin (HbCO) and sulfhemoglobin (SHb) in the blood of rats exposed to cashew seed fumes (CSF), via the dynamic exposure system. Eighteen (18) male albino rats were used; they were divided into three groups of six animals each as: control, rats exposed for two (2) hours and rats exposed four (4) hours for five days. The results showed that serum level of LDH in rats exposed to CSF was significantly $(P<0.05)$ increased compared with the control rats. The \%SHb and \%HbCO in the blood of rats exposed to CSF were significantly $(P<0.05)$ increased compared with the control rats. However there were no significant $(P>0.05)$ differences in the \% methemoglobin level of rats in all groups. This study revealed that exposure to CSF may have adverse effects on the lungs and may also result in system poisoning. This should be a cause of concern for industrial regulatory bodies who should regulate the safety of cashew factory workers.
\end{abstract}

\section{Keywords}

Cashew Seed Fume, Methemoglobin, Sulfhemoglobin, Carboxyhemoglobin, Albino Wistar Rats

Subject Areas: Toxicology

${ }^{*}$ Corresponding author.

How to cite this paper: Tope, M.T., Adedotun, I.D., Dorcas, A.T., Bode, O.M., Otaru, O.W. and Esther, A.T. (2016) Activities of Lactate Dehydrogenase, Methemoglobin, Carboxyhemoglobin and Sulfhemoglobin Concentrations in the Blood of Albino Rats Exposed to Cashew Seed Fume. Open Access Library Journal, 3: e2284. http://dx.doi.org/10.4236/oalib.1102284 


\section{Introduction}

The cashew (Anacardium occidentale) is a tree in the family of the flowering plant Ancardiaceae. The family contains 73 genera and about 600 species. Anacardium contains 8 species, native to tropical America, of which the cashew is by far the most important, economically [1]. It is a multipurpose tree of the Amazon that grows up to $15 \mathrm{~m}$ high [1] [2]. The cashew tree produces many resources and products. The bark and leaves are used medicinally. Almost all parts of cashew tree are reported to have ethno-medicinal properties [1]. The cashew nut is the fruit of the cashew tree; the cashew nut has international appeal and market value as food. Even the shell oil around the nut is used medicinally and has industrial applications in plastics and resin industries for its phenol content. The pseudo-fruit, a large pulpy and juicy part, has a fine sweet flavour and is commonly referred to as the "cashew fruit" or the "cashew apple" [3].

Cashew nuts can be extracted from cashew seeds by two main methods: oil bath and steaming method. The cashew kernel is embedded in a double-walled husk that contains toxic substances. During kernel extraction (dehusking), the husk is broken and releases Cashew Nut Shell Liquid (CNSL), a caustic and poisonous substance which has a harmful effect on the skin [4] as seen in countries where kernels are hand-extracted. Studies revealed that CNSL consists of cardanol (60\% - 65\%), cardol (15\% - 20\%) [5], polymeric material (10\%), and traces of 2-methylcardol. The natural (cold extracted) consists of: $70 \%$ anacardic acid, $8 \%$ cardol, and 5\% cardanol, with the remainder being made up of other phenols and less polar substances. The nuts within which is the kernel must be roasted to get rid of poisonous substances [6]. Burning of cashew nut shell which holds about $30 \%$ of CNSL of its total weight in furnaces produces excessive heavy dark smoke with particulate matter. This is expected considering the high concentration of carbon in the various CNSL. Fumes arising from the nuts during roasting may be irritating to the face, nostrils, and throat. The oil exuding from the nuts is very caustic and may cause skin brown marks like warts, swelling, and inflammation [7]. The mucous membranes of the mouth and throat are severely affected when it comes into contact with shell oil or the irritating fumes emitted during roasting. Pollution to the environment derived from this practice is quite profound; the smokes contaminate air and the wastewater released into the environment is also a source of contamination. Some of the pollutants expected from burning cashew shells include mainly, Carbon particles, Carbon monoxide, Nitrogen oxides and hydrocarbon residues. In the presence of sunlight, this mixture may produce ozone and chemical smog as secondary pollutants [8].

This study therefore evaluates the effects of cashew seed fumes (CSF) on methemoglobin, carboxyhemoglobin, sulfhemoglobin in the blood and lactate dehydrogenase activity in the serum of in albino rats.

\section{Materials and Methods}

\subsection{Plant Material}

Samples of A. occidentale were collected obtained from Oja-Oba market in Owo, Ondo State, Nigeria. The cashew nut was separated from the cashew apple stalk; the nuts were dried in the sun and stored under open air condition.

\subsection{Experimental Animals}

Twenty-four male albino rats (100 - 150 g) were purchased from the Department of Biochemistry, Faculty of life sciences, University of Benin, Benin City. The rats were housed and maintained under standard conditions (12 h light/dark cycles). Food (pellet from Animal care limited, Nigeria) and tap water was given ad libitum. The animals were care for in accordance with the recommendations provided in the "Guide for the Care and Use of Laboratory Animals” prepared by the university.

\subsection{Experimental Protocols}

The rats (18) were divided into three groups containing six animals each as follow:

Group 1-control (6 rats);

Group 2-rats (6 rats) exposed to cashew fume for 2 hrs per day for 5 days;

Group 3-rats (6 rats) exposed to cashew fume for 4 hrs per day for 5 days. 


\subsection{Experimental Set-Up}

The rats were exposed to cashew seed fume via inhalation for 5 days. The system consisted of a whole body exposure chamber $\left(1 \mathrm{~m}^{3}\right)$ with an air inlet at the top and air exhaust at the bottom of the chamber, following the dynamic method described by Silver [9] where there is a continuous flow of air through the chamber. Dynamic exposure systems are characterized by a continuous replacement of chamber air and test material. Inside the chamber animals were housed individually in a wire mesh unit. The fumes were introduced into the chamber using a gas pipe. For the exposure procedure rats in each group were placed in the chamber, the fumes were introduced into the chamber through a gas pipe connected to a sealed roasting can. The test groups were exposed to 200 gramms of cashew seed per hour. Cage side examination was performed at 1 hour interval to detect signs of toxicity such as chewing jaw movements, squinting, writhing, convulsion, yellowing of fur, restlessness, erection of fur, vocalization, exophthalmia, and behavioral abnormalities or even death.

\subsection{Collection of Blood Samples}

The experiment lasted for 5 days. At the end of the experimental period, the rats were sacrificed and blood samples were collected through heart puncture. The blood samples were collected into EDTA tubes for determination of methemoglobin, carboxyhemoglobin and sulfhemoglobin. Plain bottles were used to obtain serum which was centrifuged at $2500 \mathrm{rpm}$ for $15 \mathrm{~min}$ at a temperature of $4^{\circ} \mathrm{C}$; it was further assayed, for the determination of Lactate dehydrogenase activity.

\subsection{Biochemical Analysis}

\subsubsection{Determination of Blood Methaemoglobin (Hi) Levels}

Using the method described by Barbara et al. [10] (0.2 mls) of bloodwas lysed in $4 \mathrm{mls}$ of buffer $(0.1 \mathrm{~mol} / \mathrm{l}$ $\mathrm{Na}_{2} \mathrm{HPO}_{4} / \mathrm{KH}_{2} \mathrm{PO}_{4}$ ) and $6 \mathrm{mls}$ of detergent solution (10 ml/L of Triton X-100). The lysate was divided into two equal volumes (A and B). The absorbance of $A$ was measured at $630 \mathrm{~nm}$ as $\mathrm{D}_{1}$. One drop of potassium cyanide (50 g/l) was added the absorbance was read at $630 \mathrm{~nm}$ as $\mathrm{D}_{2}$. One drop of potassium ferricyanide $(50 \mathrm{~g} / \mathrm{l})$ was added to solution $\mathrm{B}$, and the absorbance was measured after 5 minutes at the same wavelength as $\mathrm{D}_{3}$. One drop of potassium cyanide was added to solution $\mathrm{B}$ and the absorbance measured as $\mathrm{D}_{4}$. All measurements were made against a reagent blank containing the buffer and detergent in the same proportion as present in the sample. The \% Hi concentration is calculated as:

$$
\operatorname{Hi}(\%)=\frac{D_{1}-D_{2}}{D_{3}-D_{4}} \times 100
$$

The tests were carried out within $1 \mathrm{~h}$ of blood samples collection.

\subsubsection{Determination of Blood Carboxyhaemoglobin (HbCO) Levels}

Blood ( $0.1 \mathrm{ml})$ was diluted in $20 \mathrm{mls}$ of $0.4 \mathrm{ml} / \mathrm{L}$ ammonia and divided into two parts. To each $20 \mathrm{mg}$ of sodium dithionite was added, the absorbance was read at $538 \mathrm{~nm}$ and $578 \mathrm{~nm}$ within 10 minutes. The \% $\mathrm{HbCO}$ was calculated as described by Barbara et al. [10]

$$
\% \mathrm{HbCO}=\frac{\left\{2.44 \times \mathrm{A}^{538}\right\}}{\mathrm{A}^{578}}-2.68
$$

\subsubsection{Determination of Blood Sulfhemoglobin (SHb) Levels}

Following the method of Barbara et al. [10], $10 \mathrm{mls}$ of $(20 \mathrm{ml} / \mathrm{l})$ of Triton X-100 was added to $0.1 \mathrm{ml}$ of blood. The absorbance (A) was read at $620 \mathrm{~nm}$ (total $\mathrm{Hb}$ ). One drop of $50 \mathrm{~g} / \mathrm{l}$ of potassium cyanide was added the solution was allowed to stand for 5 minutes. Absorbance A was read at $620 \mathrm{~nm}$ and at $578 \mathrm{~nm}$. The \% SHb was calculated as:

$$
\operatorname{SHb}(\%)=\frac{2 \times \mathrm{A}^{620} \mathrm{SHb}}{\mathrm{A}^{620} \mathrm{HbO}_{2}}
$$

where 


$$
\mathrm{A}^{620} \mathrm{HbO}_{2}=\frac{\text { Absorbance read at } 578 \mathrm{~nm}}{\text { convertion factor }}
$$

And

$$
\mathrm{A}^{620} \mathrm{SHb}=\mathrm{A}^{620} \text { total } \mathrm{Hb}-\mathrm{A}^{620} \mathrm{HbO}_{2}
$$

\subsubsection{Determination of Lactate Dehydrogenase Activity}

The activity of Lactate Dehydrogenase (LD) concentration in the serum of experimental rats was determined using the UV method according the recommendations of the Deutsche Gesellschaft furKlinische Chemie [11] using diagnostic kits obtained from Randox Laboratories, UK.

\subsection{Statistical Analysis}

Values are expressed as the mean \pm SD. Results were statistically analyzed by one-way analysis of variance (ANOVA) for differences between means of different groups. All data were analyzed using SPSS statistical package (SPSS Inc.) version 13.0.

\section{Results}

Table 1 shows the \% Methemoglobin (Hi), Carboxyhemoglobin (HbCO), and Sulfhemoglobin (SHb), concentrations in the blood of experimental rats. There was an increase in the blood methemoglobin levels of rats exposed to cashew seed fumes compared with the control group, although the increase was not significantly ( $p>$ $0.05)$ different from the control group. As shown in the table, there was a significantly $(p<0.05)$ higher level of blood carboxyhemoglobin in rats exposed to cashew seed for 4 hrs for 5 days compared with those exposed for 2 hrs for 5 days and the control groups. Although the 2 hrs/day exposed groups showed an increase in the carboxyhemoglobin level from that of the control, the difference was not significant $(p>0.05)$. The blood sulfhemoglobin level of cashew seed exposed groups were significantly higher $(p<0.05)$ compared with the control group, the sulfhemoglobin levels in the exposed groups were dose dependent.

Table 2 presents the results of lactate dehydrogenase (LDH) activity of in the serum of experimental rats. The result revealed activity of LDH was significantly $(p<0.05)$ higher in the serum of rats exposed to cashew seed fume at 2 hours and 4 hours daily when compared with the control.

\section{Discussion}

Methemoglobin (Hi) is a form of the oxygen-carrying metalloproteinase hemoglobin, in which the iron in the

\section{Table 1. \% Methemoglobin (Hi), carboxyhemoglobin (HbCO), sulfhemoglobin (SHb), in the blood of experimental rats.}

\begin{tabular}{cccccc}
\hline Group & Time of Exposure (hrs/day) & \% Hi & \% HbCO & SHb \\
1 & 0 & $4.07 \pm 1.00$ & $0.55 \pm 0.07$ & $0.84 \pm 0.04^{\mathrm{bc}}$ \\
2 & 2 & $5.22 \pm 0.88$ & $0.66 \pm 0.04$ & $2.25 \pm 0.49^{\mathrm{a}}$ & \\
3 & 4 & $4.38 \pm 0.57$ & $0.82 \pm 0.08^{\mathrm{ab}}$ & $2.69 \pm 0.22^{\mathrm{a}}$ \\
\hline
\end{tabular}

The results are shown as means \pm SE $(n=6)$. The different letters in the same column indicates a statistical difference $(p<0.05)$. Subscripts ${ }^{\text {a,b }}$ and ${ }^{c}$ indicates a statistical difference $(p<0.05)$ from groups 1,2 , and 3 respectively.

Table 2. Lactate dehydrogenase (LDH) activity in the serum of experimental rats.

\begin{tabular}{ccc}
\hline GROUP & Time of Exposure (hrs/day) & Lactate Dehydrogenase (U/I) \\
\hline 1 & 0 & $8.25 \pm 0.00^{\mathrm{bc}}$ \\
2 & 2 & $11.57 \pm 0.81^{\mathrm{a}}$ \\
3 & 4 & $10.32 \pm 0.77^{\mathrm{a}}$ \\
\hline
\end{tabular}

The results are shown as means \pm SE $(\mathrm{n}=6)$. The different letters in the same column indicates a statistical difference $(p<0.05)$. Subscripts ${ }^{\mathrm{a}, \mathrm{b}}$ and ${ }^{\mathrm{c}}$ indicates a statistical difference $(p<0.05)$ from groups 1,2 , and 3 respectively. 
heme group is in the $\mathrm{Fe}^{3+}$ (ferric) state, not the $\mathrm{Fe}^{2+}$ (ferrous) of normal hemoglobin. Methemoglobin cannot bind oxygen, unlike oxy-hemoglobin [12]. An excessive amount of Hi occurs as a result of oxidation of haemoglobin $(\mathrm{Hb})$ by drugs and chemicals such as phenacetin, sulphonamides, aniline dyes, nitrates and nitrites. Methemoglobinemia can cause cyanosis [10]. As shown in Table 1, the result of revealed that the \% methemoglobin concentration in the blood of rats exposed to CSF was slightly higher compared with the control group, although the differences was not statistically significant, This may be due to competitive binding of oxygen to haemoglobin which may have converted $\mathrm{Fe}^{3+}$ to $\mathrm{Fe}^{2+}$ hence leading to a reversal of the methemoglobin level in the blood of the experimental rats or due to action of methemoglobin reductase responsible for converting methemoglobin back to hemoglobin.

Sulfhemoglobin pigment is a greenish derivative of hemoglobin which cannot be converted back to normal, functional hemoglobin. It is a rare blood condition that occurs when a sulfur atom is incorporated into the hemoglobin molecule. When hydrogen sulfide (or sulfide ions) combines with ferric ions in the blood, the blood is incapable of carrying oxygen. Sulfhemoglobin causes cyanosis even at low blood levels [13]. The result revealed that \% sulfhemoglobin concentration in the blood of rats exposed to cashew seed fume was significantly increased when compared with the control. This may be due to the irreversible binding of sulfur to hemoglobin in the exposed rat.

Carboxyhemoglobin (HbCo) is a stable complex of carbon monoxide and hemoglobin that forms in red blood cells upon contact with carbon monoxide [14]. Carbon monoxide binds hemoglobin at the same sites as oxygen but with a higher affinity than oxygen [15], hence it cannot be released easily thus leading to accumulation of carbon monoxide. Carbonmonoxide is produced during normal metabolism, but carbon monoxide inhalation raises the blood levels of HbCO severally from its normal concentrations. The significant increase in the \% HbCO concentration in the blood of exposed rats may be due to inhalation of carbon particles, carbon monoxide and hydrocarbon residues released during the roasting of cashew seed. Large quantities of carbonmonoxide hinder the ability of hemoglobin to deliver oxygen to the body [16], and this leads to oxygen deprivation in the body causing tiredness, dizziness, and unconsciousness.

Lactate dehydrogenase (LDH) is a cytoplasmic enzyme present in essentially all major organs of the body. The extracellular appearance of LDH is used to detect cell damage or cell death [17]. LDH is released into the peripheral blood after cell death caused either by exposure to bacterial toxins, chemical poisonings, ischaemia, excess heat or cold, starvation, dehydration, injury, and after ingestion of certain drugs [18], as shown in Table 2, the LDH activities of exposed rats was significantly increased compared with control, this may be due to chemical poisoning of the blood resulting from exposure to carbon particles, carbon monoxide, nitrogen oxides and hydrocarbon residues released during the roasting of cashew seed. The increased activity of LDH is implicative of myocardial infarction and or hepatic injury [19] [20].

\section{Conclusion}

Cashew seed fume is unhealthy and its inhalation especially for a long period of time could be very toxic as revealed by the significant increased concentration of carboxyhemoglobin, sulfhemoglobin in the blood and the significant increased activities of lactate dehydrogenase activity in the serum of exposed rats. Processing of cashew nuts locally should be discouraged by the community and prohibited by the government, while industrial production of cashew nuts should be properly looked into by the government to ensure that the workers are adequately safe and protected from exposure to cashew seed fume. Further studies should be carried out to determine the effects of cashew seed fume exposure on humans.

\section{References}

[1] Morton, J.F. (1987) Cashew Apple. Fruits of Warm Climates, 11, 239-240.

[2] De Souza, C.P., Mendes, N.M., Janotti-Passos, L.K. and Pereira, J.P. (1992) The Use of the Shell of Cashew Nut, Anacardium occidentale, as an Alternative Molluscacide. Revista do Instituto de Medicina Tropical de São Paulo, 34, 459-466.

[3] Dare, S.S., Hamman, W.O., Musa, S., Goji, A.D.T., Oyewale, A.A., Abba, S. and Ezekiel, I. (2011) Effects of Aqueous Extract of Anacardium occidentale (Cashew) Leaf on Pregnancy Outcome of Wistar Rats. International Journal of Animal and Veterinary Advances, 3, 77-82.

[4] ITDG (2001) The Cashew Nut Processing. Intermediate Technology, 1, 1-8. 
[5] Alexander, H.T. (2008) A Nutty Chemical. Chemical and Engineering News, 86, 26-27. http://dx.doi.org/10.1021/cen-v086n036.p026

[6] Master, A., Santosh, K.D. and Sachidananda, P. (2006) Eco-Consciousness for Poisonous and Injurious Plants among Urban Dwellers of Bhubaneswar, Orissa. Journal of Human Ecology, 19, 239-248.

[7] Ravil, K. and Patil, M.B. (2009) Evaluation of Anacardium occidentale Gum as Gelling Agent in Acelofenac Gel. Journal of PharmTech Research, 3, 695-704.

[8] John, B. (2006) 21st Century Children’s Encyclopedia. Academic (India) Publishers, New Delhi, 13-14.

[9] Silver, S.D. (1946) Constant Flow Gassing Chambers: Principles Influencing Design and Operation. Journal of Laboratory and Clinical Medicine, 31, 1153-1161.

[10] Barbara, J.B., Imelda, B., Micheal, A.L. and Lewis, M.S. (2012) Laboratory Methods Used in the Investigation of the Hemolytic Anaemia. In: Dacie and Lewis Practical Haematology, 11th Edition, Church Hill Living Stone, 240-242.

[11] Deutsche Gesellschaft fur Klinische Chemie (DGKC) (1970) Determination of Lactate Dehydrogenase Activity Using UV Method. Journal of Clinical Chemistry and Clinical Biochemistry, 8, 658.

[12] Vasudevan, D.M., Vaidynath, K. and Sreekumari, S. (2013) Biochemistry for Medical Students. 7th Edition, Jaypee Brothers Medical Publisher Ltd., New Delhi, 346-360.

[13] Flexman, A.M., Del Vicario, G. and Schwarz, S.K. (2007) Dark Green Blood in the Operating Theatre. The Lancet, 369, 9577-9578.

[14] Goldfrank, L., Flomenbaum, N., Lewin, N., Howland, M.A., Hoffman, R. and Nelson, L. (2002) Carbon Monoxide. In: Goldfrank's Toxicologic Emergencies, 7th Edition, McGraw-Hill, New York, 1689-1704.

[15] Berg, J. (2011) Chapter 10: Regulatory Strategies. Berg, T. and Biochemistry, S., Eds., 7th Edition, WH. Freeman and Company Limited, New York.

[16] Bateman, D.N. (2003) Carbon Monoxide. Medicine, 31, 41-42. http://dx.doi.org/10.1383/medc.31.10.41.27810

[17] Lott, J.A. and Nemensanszky, E. (1987) Lactate Dehydrogenase. In: Lott, J.A., Wolf, P.L. and Sawhney, A.K., Eds., Clinical Enzymology: A Case-Oriented Approach, Field and Rich/Year Book, New York, 213-244.

[18] Glick, J.H. (1969) Serum Lactate Dehydrogenase Isoenzyme and Total Lactate Dehydrogenase Values in Health and Disease, and Clinical Evaluation of These Tests by Means of Discriminant Analysis. American Journal of Clinical Pathology, 52, 320-328.

[19] Warren, E.C., Wacker, M.D., David, D., Ulmer, M.D., Bert, L. and Vallee, M.D. (1956) Metalloeneymes and Myocardial Infarction-Malic and Lactic Dehydrogenase Activities and Zinc Concentrations in Serum. The New England Journal of Medicine, 255, 449-456. http://dx.doi.org/10.1056/NEJM195609062551001

[20] Shahjahan, M., Jainu, S.M. and Devi, C.S.S. (2004) Effect of Solanum trilobatum against Carbon Tetrachloride Induced Hepatic Damage in Albino Rats. Indian Journal of Medical Research, 120, 194-198. 